\title{
GACMA sitúa al arte emergente malagueño en el contexto "glocal"
}

GACMA places the emerging art of Malaga in the "glocal" context

Gabriela Giménez de la Riva

Universidad de Málaga, España (ggimenezdelariva@gmail.com)

Recibido el 20 de Diciembre de 2016; revisado el 27 de Enero de 2017; aceptado el 29 de Enero de 2017; publicado el 1 de Marzo de 2017

A menudo, quienes por nuestra formación nos dedicamos a mirar al arte, nos olvidamos que éste no se compone sólo de la capa que forma la imagen que vemos. Parece que pensáramos que el arte se ha hecho siempre a sí mismo. Hay un importante desnivel que salvar entre el estudio del arte como imagen, y la realidad de la factura de las obras. En este sentido, se hace necesario mantenerse cerca de quienes están haciendo el arte hoy para que, por medio de su conocimiento aplicado, podamos relativizar lo descomunal e inconmensurable de las ideas, cuando se sostienen sólo por sí mismas. Conocer a quienes toman acción y producen el arte es, en consecuencia, aprender a perder idealismo.

GACMA ha acogido desde el 25 de noviembre de 2016 al 25 de enero de 2017 la exposición Under 35 que, desde 2014, reúne a artistas emergentes andaluces. Son todos jóvenes - por debajo de 45 años- y emergentes -under 35-, y, en algo, vinculados a Málaga. La exposición, que ya anda en su tercera edición, surge en el marco de un proyecto I+D+i del Cei Biotic de la Universidad de Granada -"Análisis de Mercado del Arte Emergente en Andalucía y desarrollo de nuevos métodos para la estimación del valor de las obras y la predicción del éxito de los artistas en el mercado global"- que pone su foco en la entrada al mercado de los artistas emergentes en Málaga. Under 35 pretende, a través de sus ediciones, hacer seguimiento de los artistas que participan en ella y servir en sí misma de estudio de mercado y análisis de cómo evolucionan las carreras de los artistas emergentes andaluces en sus albores.

En la justificación expositiva, se entiende por emergente al "joven ambicioso y competente, cuyo trabajo es fruto de la disciplina diaria y de una constante situación de alerta: premios, concursos, becas, subvenciones, participación en exposiciones colectivas"1. A los que se han mantenido en la muestra desde 2014 -Luis Alhama, Dadi

${ }^{1}$ GACMA, Dossier de sala, "GACMA presenta la exposición \#UNDER35 (3rd edition) una selección de 30 artistas emergentes andaluces”. pp. 1- 2. 
Dreucol, Lola Guerrera, Federico Miró, Violeta Niebla y Florencia Rojas-, se les suman algunos de los que ya participaron en la segunda edición -Pablo Caro, Arturo Comas, Gonzalo Fuentes, Clara Gómez Campos, Alejandro Martín Parra, Bartolomé Montes, Mercedes Pimiento, Eugenio Rivas, Zeus Sánchez, Virginia Rota, José Luis Valverde y Elo Vázquez-, y algunos talentos de nueva incorporación: Miguel Azuaga, Efrén Calderón, Christian Lagata, Juan López López, Victoria Maldonado, Javier Map, Pablo Mesa, Antonio Navarro, Nano Orte, Fran Pérez Rus, Francisco J. Valverde y Andy G. Vidal.

La exposición, comisariada por Antonella Montinaro (GACMA), enfatiza, de un modo u otro, algunos puntos a tener en cuenta cuando miramos al "arte joven en nuestra zona de influencia", es decir, el que se desarrolla y expone, en este caso, en Málaga y Andalucía. Por un lado, resulta interesante comprobar cómo el discurso expositivo está enraizado en el marco malagueño y andaluz, pero, tan sólo como centro geográfico inevitable y necesario para la reunión de estos artistas. El contexto "glocal", que Under 35 lleva investigando desde su creación, en que se mueven todos los artistas under 35, es algo que, lógicamente, no es sólo propio de los artistas que exponen en Málaga/Andalucía, sino algo natural en el arte emergente a nivel internacional en este momento actual de interconexión e inmediatez de la comunicación. El arte en este contexto ha adquirido una serie de connotaciones que hasta ahora no había ensayado. El modo en que los artistas jóvenes se conocen y se relacionan ha variado y se ha multiplicado en posibilidades de forma extraordinaria. La absoluta expansión de las redes sociales, junto a otros medios más tradicionales, como los circuitos de ferias y festivales, hacen que los artistas jóvenes de cada ciudad europea o, al fin, del contexto occidental, sólo tengan que compartir sus referentes -en cuanto a instituciones, galerías y centros donde ocurra el arte- para que puedan fácilmente entrar en contacto con nuevos artistas a millas de ellos.

Se añade, dentro de esta observación de lo "glocal", el hecho de que muchos de estos artistas que en origen han producido o han expuesto con asiduidad en Málaga, ya se han trasladado a otras ciudades de España o, también, del exterior. Es decir, la nómina de artistas presentados no sólo es de orígenes variados sino que ya se han insertado en otros contextos artísticos y, a menudo, su arte participa con más frecuencia del que ocurre en Bélgica, Países Bajos, Alemania o Inglaterra, que de lo que se respira en Málaga.

Leyendo la hoja de sala que da noticia del proyecto de investigación en que se enmarca la exposición y las biografías de cada artista, todavía son evidentes dos cosas más: que los artistas que exponen no se ciñen al círculo más o menos oficial, por así decir, de la Facultad de Bellas Artes del Ejido, sino que están contemplados también los provenientes de otros núcleos como Cienfuegos, o artistas transdisciplinares insertos a la vez en otros círculos artísticos de la ciudad, como los de poesía; o artistas que siquiera provienen de los estudios superiores a los que asociamos comúnmente las Bellas Artes y que se han desarrollado de forma autodidacta, desde otros estudios, o movidos por una 
sólida voluntad y determinación por hacer. Dejando a un lado la formación que han seguido, tampoco hay gran cohesión en cuanto a técnicas y formatos, y esto es indicio aplicable al arte actual en su amplitud.

Dentro ya de la sala, el planteamiento de la exposición se estructura atendiendo a los dos niveles de altura que ofrece el local de GACMA. El diseño expositivo, en este sentido, resulta más eficiente que llamativo o novedoso. Probablemente, en una exposición colectiva de estas características, con artistas de distintas procedencias y formatos, aunados por rasgos tan generales como la edad y el escenario común, se haga complicado el desarrollo de un discurso más complejo. Quizá ésta sea la mejor manera de poner orden entre todas estas obras.

En la sala principal, se exhiben los grandes formatos y las técnicas más tradicionales, lienzos, fotografías y dibujos de dimensiones medianas y grandes, y también un tipo de tapiz contemporáneo, Estudio para una bandera europea, 2015, obra de Pablo Mesa Capella, quien, a partir del diseño real de le bandera de la Unión Europea, juega con las ideas que ésta pretende representar. Junto a él, obras de Dadi Dreucol, José Luis y Francisco Javier Valverde, y obra del artista murciano Javier Map quien ha estado exponiendo en Casa Sostoa de Málaga simultáneamente. La producción de este artista afincado en Andalucía se desarrolla en buena medida en sus dibujos -grafitos y lápiz sobre papel- que despliegan un lado emocionante y siniestro de lo que tenemos por verdadero y cotidiano. En Under 35 ha estado exponiendo uno de los Lugares donde desaparecer (VII), en los cuales se da un inquietante equilibrio en la naturaleza, quizá amenazado por lo radical monócromo del mismo dibujo, que introduce la artificialidad en el paisaje.

La parte superior de la sala es un pasillo que se eleva con escaleras formando una especie de atrio alrededor del espacio central. Este espacio se ha aprovechado para colgar las obras de pequeño formato. Aquí hay dibujos, fotografías, o gouaches. Clara Gómez Campos expone su témpera Mujer con turbante blanco [1], 2016, una relectura de los pequeños formatos y los retratos típicos con turbantes de Van Eyck. Ella descontextualiza el turbante y se lo da como toalla para el pelo a una bañista que aparece sobre un fondo de tiburones. En esta sección, también, cuelgan las interesantes obras fotográficas de Virginia Rota Amor hierático, 2015, y Elo Vázquez, In between, 2015.

Una tercera sala es la que llaman "escaparate" y es la que se ve desde el exterior, a través de la cristalera. Aquí aparecen diferenciados los trabajos que requieren mayor espacio, las piezas escultóricas, y las obras audiovisuales. Las esculturas se exponen en el mismo suelo de la habitación a veces; así encontramos, por ejemplo, Los inciertos [2], 2014 de Luis Alhama, un gran embudo de metal que esconde casi imperceptibles figuras de poliéster y polvo de mármol que dejan asomar sólo sus pies. Las de menor formato, en 
cambio, se muestran en una vitrina de mesa. Aquí están, entre otros, las piezas de Victoria Maldonado o las de Efrén Calderón [3], la serie Sin título, 2016 que ha sido su proyecto dentro de la residencia Creadores de La Térmica, en que ha participado este año. La obra trabaja con el material sobrante de su actividad como grafitero; con la pintura excedente, modela pequeños ladrillos que adquieren carácter más volumétrico que bidimensional, como suele hacer el material pictórico.
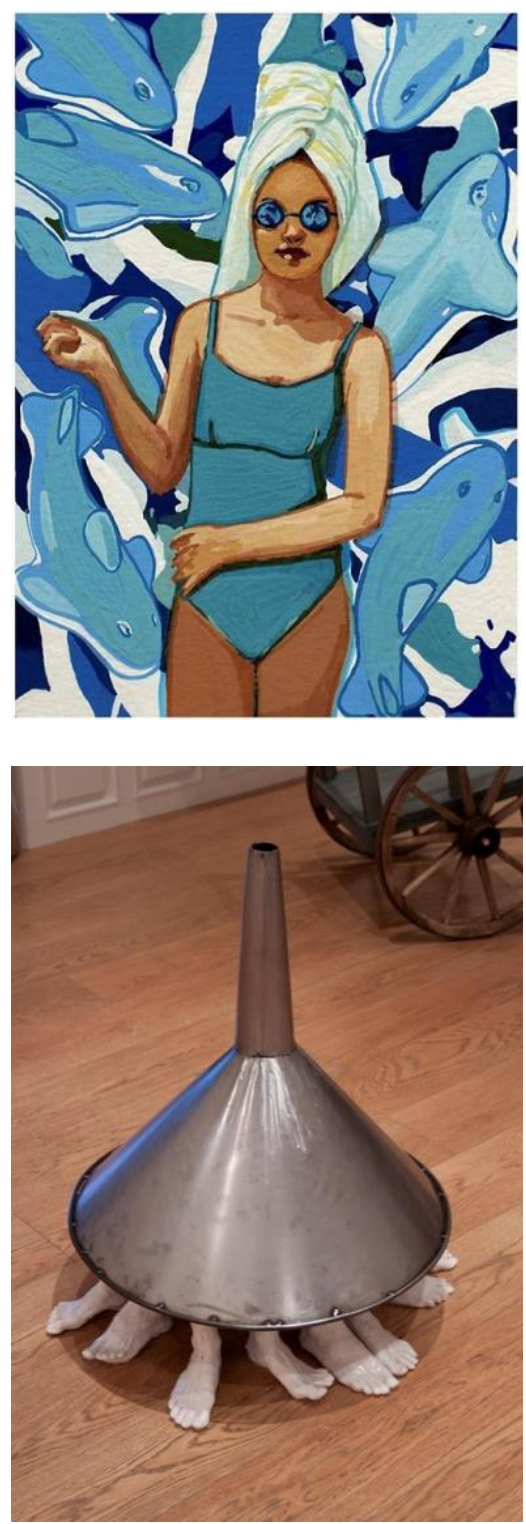

1. Mujer con turbante blanco, Clara Gómez Campos, 2006. Témpera sobre papel

2. Los inciertos, Luis Alhama, 2014.

Metal, resina de poliéster con polvo de mármol 


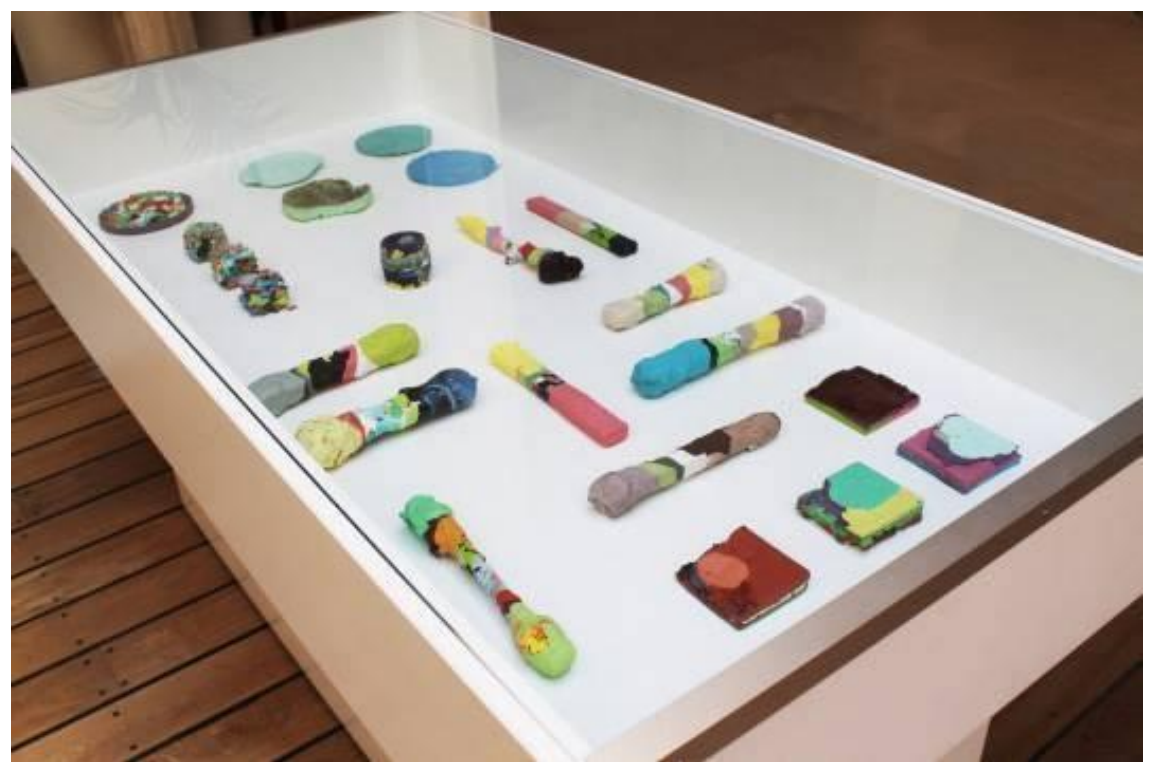

3. Stick, Efrén Calderón, 2016.

Pintura plástica sobre madera

Terminado el recorrido por estas muestras del arte emergente que reúne Málaga, como dice Cecilio Rodríguez (GACMA), no están ni mucho menos todos los nombres de quienes hoy son jóvenes, emergentes, y con buenas perspectivas en este mercado en la ciudad. Aunque circunstancias concretas y el propio límite espacial no permitan que otros hayan estado en estas salas, los podemos ver en el resto de centros del circuito artístico de Málaga y su provincia en los que, con frecuencia, se les cede generosamente protagonismo.

Exposiciones como éstas, aunque sean confusas por la gran cantidad de circunstancias que se ven obligadas a conciliar, son a la vez necesarias para conocer y situar en su contexto el arte que está teniendo lugar cerca de nosotros y, al menos, tomarlas por archivo desde el que comenzar a seguir la obra de todos estos artistas under 35. 